\title{
Périgueux - 16 rue du Bac
}

$\mathrm{n}^{\circ} 026110$

\section{Laurent Grimbert}

\section{(2) OpenEdition}

Journals

Édition électronique

URL : http://journals.openedition.org/adlfi/16421

ISSN : 2114-0502

Éditeur

Ministère de la culture

Référence électronique

Laurent Grimbert, «Périgueux - 16 rue du Bac », ADLFI. Archéologie de la France - Informations [En ligne], Aquitaine, mis en ligne le 10 février 2016, consulté le 19 avril 2019. URL : http:// journals.openedition.org/adlfi/16421

Ce document a été généré automatiquement le 19 avril 2019

(c) Ministère de la Culture et de la Communication, CNRS 


\section{Périgueux - 16 rue du Bac}

$n^{\circ} 026110$

\section{Laurent Grimbert}

Lien Atlas (MCC) :

http://atlas.patrimoines.culture.fr/atlas/trunk/index.php?

ap_theme=DOM_2.01.02\&ap_bbox=-0.674;45.174;0.747;45.214

1 La reconnaissance archéologique du 16 rue du Bac est liée à un projet de construction d'une maison individuelle.

2 Le sondage réalisé $\left(35 \mathrm{~m}^{2}\right)$ a révélé la présence d'un cimetière moderne totalement inédit. Le niveau d'apparition des sépultures se situe environ à $0,75 \mathrm{~m}$ de la surface. Le nettoyage rapide de quelques individus a révélé une importante densité de sépultures avec de nombreux recoupements et des pratiques de réduction avérées.

3 La création de ce cimetière perturbe des éléments antérieurs, notamment deux fondations de murs, composées de blocs calcaires sans liant, disposées à angle droit. Le mur nord-sud (ST5) est recoupé par la mise en place de la sépulture ST2. Le mur est-ouest, lui, (ST4) sert d'appui à une sépulture (ST3). Le niveau d'arasement de ces deux constructions coïncide avec celui d'un niveau de sol en terre battue, lui-même recouvert par un remblai de fragments de tuiles (effondrement de toiture ?). La présence d'un tesson dans ce niveau de sol en terre battue permet de situer cette phase d'occupation à l'époque moderne. Elle est sans doute antérieure de peu à la mise en place du cimetière dont l'installation dans ce secteur se situe entre le $\mathrm{XVI}^{\mathrm{e}}$ et la fin $\mathrm{du} \mathrm{XVIII}^{\mathrm{e}} \mathrm{s}$. Cette datation a été confirmée par une analyse radiocarbone d'ossements d'une des sépultures.

4 Les connaissances archéologiques sur le secteur sont extrêmement pauvres. La zone n'est bâtie qu'au début du XIX ${ }^{e}$ s., lors du percement du boulevard Fénelon et de la création du pont Saint-Georges. Il n'est pas possible de rattacher le cimetière ou les constructions mises au jour à une occupation précise. La plus proche église reconnue est l'église SaintHilaire, située à quelques centaines de mètres au sud. L'occupation antérieure au cimetière doit correspondre à un petit bâtiment, peut-être d'usage agricole, dans ce 
secteur peu urbanisé de Périgueux. Aucun indice lié à l'occupation antique n'a été mis au jour.

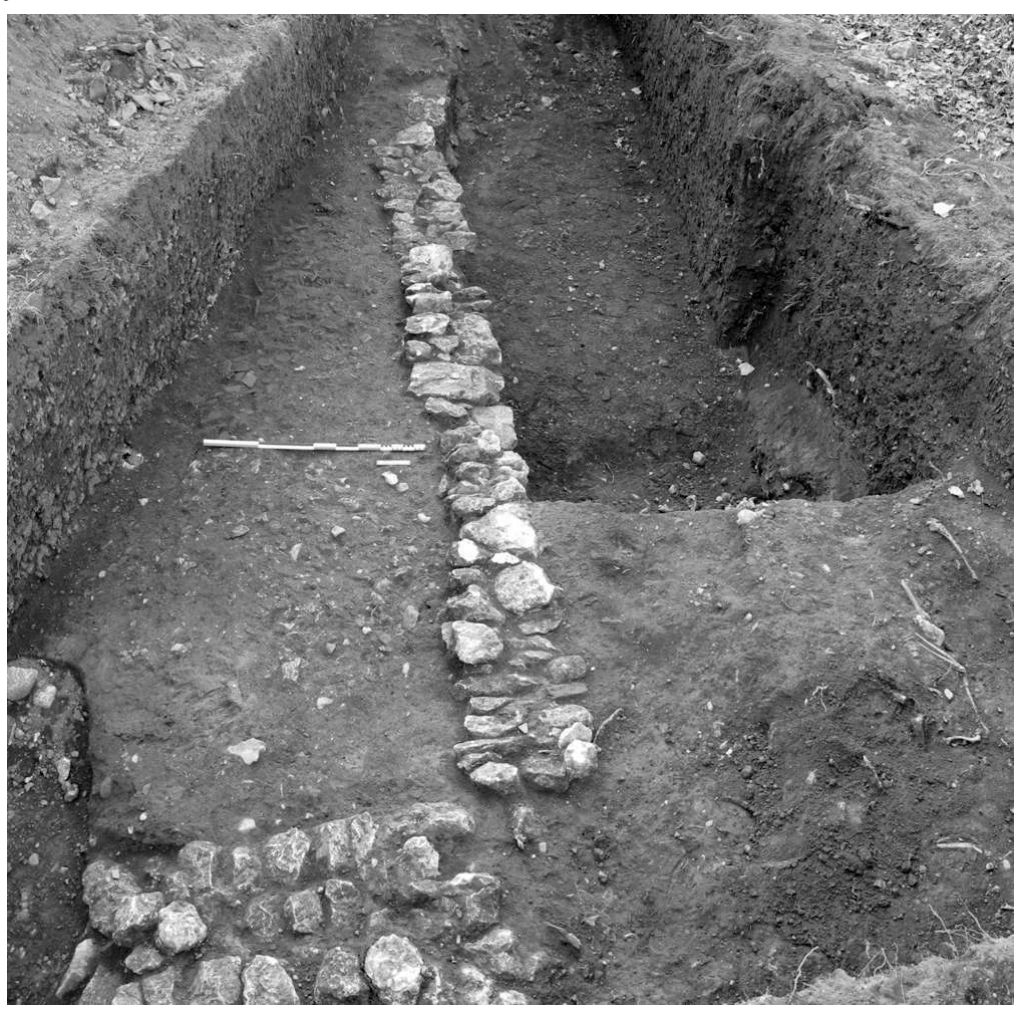

Fig. 1

Vue générale des structures

Cliché : L. Grimbert, Inrap

\section{INDEX}

Index chronologique : Temps Modernes

Index géographique : Aquitaine, Dordogne (24), Périgueux operation Opération préventive de diagnostic (OPD)

Mots-clés : sépulture, cimetière

\section{AUTEURS}

\section{LAURENT GRIMBERT}

Inrap 